\title{
A practical guide for using lithium halocarbenoids in homologation reactions
}

\author{
Serena Monticelli ${ }^{1} \cdot$ Marta Rui $^{1} \cdot$ Laura Castoldi $^{1} \cdot$ Giada Missere $^{1} \cdot$ Vittorio Pace $^{1}$ (D)
}

Received: 7 April 2018/Accepted: 13 May 2018/Published online: 11 June 2018

(C) The Author(s) 2018

\section{Abstract}

Lithium halocarbenoids are versatile reagents for accomplishing homologation processes. The fast $\alpha$-elimination they suffer has been considered an important limitation for their extensive use. Herein, we present a series of practical considerations for an effective employment in the homologation of selected carbon electrophiles.

\section{Graphical abstract}

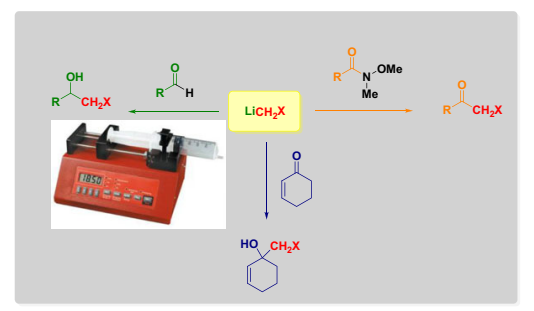

Keywords Lithiation · Carbenoids · Organometallics

\section{Introduction}

Methylenating agents are recognized as valuable synthetic tools in homologation reactions, allowing the formal insertion of a methylene unit (i.e., $\mathrm{CH}_{2}$ ) into a given preformed bond. Classical examples of homologation processes are represented by the carbon chain extension or the ring expansion of carbonyl compounds $[1,2]$.

Carbenoidic reagents play a prominent role within the plethora of homologating agents [3-6]. The term carbenoid was introduced by the pioneers in the field Closs and Moss

Electronic supplementary material The online version of this article (https://doi.org/10.1007/s00706-018-2232-9) contains supplementary material, which is available to authorized users.

Vittorio Pace

vittorio.pace@univie.ac.at

1 Department of Pharmaceutical Chemistry, University of Vienna, Vienna, Austria who defined their chemical reactivity "qualitatively analogous to those of carbenes without necessarily being free divalent carbon species" [7]. Accordingly, organometallic compounds containing a metal atom (e.g., $\mathrm{Li}, \mathrm{Mg}$ ) and, at least one electronegative element (e.g., halogen) linked to the same carbon, have been referred to as carbenoids, thus considering their carbene-like features [8].

A significant advancement in the field originated from the work of Gert Köbrich and coworkers in the 1960s [9]. These milestones still represent the key concepts in carbenoid chemistry and put the bases for the rational design and understanding of reactions involving these versatile synthetic tools. The concomitant presence of an electrondonating and electron-withdrawing substituent at the carbon center determines the so-called ambiphilicity of these reagents $[5,10]$. Thus, carbenoids display a dual reactivity ranging from nucleophilic to electrophilic [6, 11, 12]. Depending on the experimental conditions, they may selectively exhibit only one of these two properties [13-17]: it is normally accepted that the nucleophilic 


\section{Scheme 1}

\section{Nature of the Metal}

Temperature
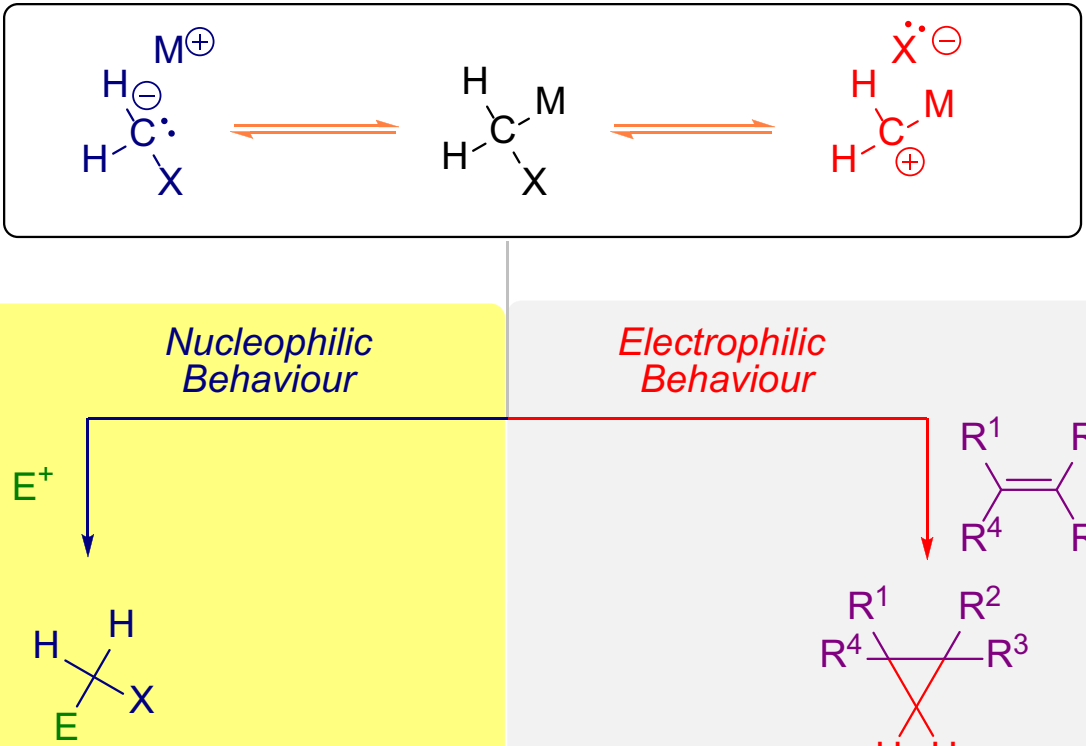

\section{Nucleophilic}

Behaviour

Electrophilic

Behaviour
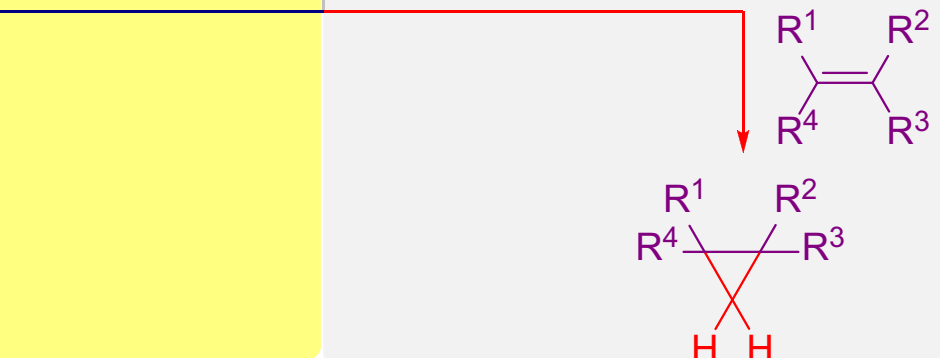

Table 1 Controlled generation of Li-carbenoid, $\mathrm{LiCH}_{2} \mathrm{Cl}$<smiles>O=Cc1ccccc1</smiles>

1
1) $\mathrm{ICH}_{2} \mathrm{Cl}$ (3.0 equiv) MeLi-LiBr (1.5 M, 2.8 equiv) THF, $1 \mathrm{~h}$

2) $\mathrm{NH}_{4} \mathrm{Cl}$ (aq.)<smiles>OC(CCl)c1ccccc1</smiles>

$2 a$<smiles>CC(O)c1ccccc1</smiles>

\begin{tabular}{|c|c|c|c|c|}
\hline Entry & $T /{ }^{\circ} \mathrm{C}$ & $\mathbf{2} \mathbf{a} / \%$ & $3 / \%$ & $4 / \%$ \\
\hline $1^{\mathrm{a}}$ & -78 & 94 & 0 & 0 \\
\hline $2^{\mathrm{a}}$ & -65 & 94 & 0 & 0 \\
\hline $3^{a}$ & -55 & 94 & 0 & 3 \\
\hline $4^{a}$ & -45 & 95 & 0 & 2 \\
\hline $5^{a}$ & -35 & 88 & 0 & 3 \\
\hline $6^{\mathrm{a}}$ & -25 & 85 & 0 & 5 \\
\hline $7^{b}$ & -25 & 93 & 0 & 0 \\
\hline $8^{a}$ & -15 & 89 & 0 & 4 \\
\hline $9^{\mathrm{a}}$ & -5 & 65 & 8 & 6 \\
\hline $10^{\mathrm{a}}$ & 0 & 68 & 10 & 9 \\
\hline $11^{\mathrm{a}}$ & 20 & 25 & 49 & 20 \\
\hline $12^{\mathrm{c}}$ & 20 & 26 & 60 & 4 \\
\hline
\end{tabular}

${ }^{\mathrm{a}} 0.200 \mathrm{~cm}^{3} / \mathrm{min}$ drop rate of $\mathrm{MeLi}-\mathrm{LiBr}$

${ }^{b} 0.400 \mathrm{~cm}^{3} / \mathrm{min}$ drop rate of MeLi-LiBr ${ }^{\mathrm{c}} 0.050 \mathrm{~cm}^{3} / \mathrm{min}$ drop rate of $\mathrm{MeLi}-\mathrm{LiBr}$ 
Table 2 Temperature dependency of different halomethyl carbenoids

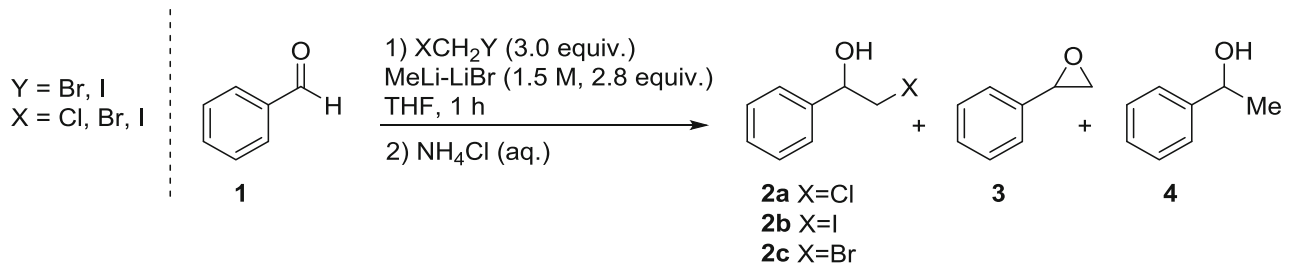

\begin{tabular}{|c|c|c|c|c|c|c|c|c|c|c|}
\hline \multirow[t]{2}{*}{ Entry } & \multirow[t]{2}{*}{$T /^{\circ} \mathrm{C}$} & \multicolumn{3}{|l|}{$\mathrm{CH}_{2} \mathrm{I}_{2}$} & \multicolumn{3}{|c|}{$\mathrm{CH}_{2} \mathrm{Br}_{2}$} & \multicolumn{3}{|c|}{$\mathrm{ICH}_{2} \mathrm{Br}$} \\
\hline & & $2 \mathbf{b} / \%$ & $3 / \%$ & $4 / \%$ & $2 \mathbf{c} / \%$ & $3 / \%$ & $4 / \%$ & $2 \mathrm{c} / \%$ & $3 / \%$ & $4 / \%$ \\
\hline 1 & -78 & 90 & 3 & 2 & 78 & 0 & 5 & 78 & 0 & 0 \\
\hline 2 & -65 & 81 & 2 & 12 & 62 & 0 & 24 & 79 & 4 & 3 \\
\hline 3 & -55 & 86 & 3 & 5 & 71 & 0 & 19 & 84 & 3 & 5 \\
\hline 4 & -45 & 68 & 24 & 4 & 90 & 0 & 5 & 81 & 7 & 3 \\
\hline 5 & -35 & 45 & 35 & 11 & 85 & 0 & 7 & 87 & 7 & 2 \\
\hline 6 & -25 & 45 & 41 & 5 & 39 & 5 & 48 & 64 & 28 & 3 \\
\hline 7 & -15 & 32 & 39 & 18 & 46 & 10 & 34 & 52 & 40 & 3 \\
\hline 8 & -5 & 22 & 54 & 4 & 0 & 20 & 68 & 34 & 12 & 51 \\
\hline 9 & 0 & 23 & 54 & 10 & 4 & 16 & 66 & 0 & 16 & 75 \\
\hline
\end{tabular}

behavior is shown at low temperatures, while their electrophilicity comes into play at higher temperatures (Scheme 1) $[6,18,19]$. This key characteristic of carbenoid reagents can be explained taking into consideration structures, which in principle can provide two different ionization forms. On the one hand, a negative charge is localized at the carbon atom (i.e., it becomes nucleophilic), while in the other case the carbon atom brings a positive charge (i.e., it becomes electrophilic).

Given these premises, one may individuate two different reactions categories in which carbenoids are involved: (1) nucleophilic additions (eventually followed by elimination); (2) cyclopropanation-type processes (SimmonsSmith like chemistry) [20,21]. It is important to stress that carbenoids of lithium and magnesium, because of their excellent nucleophilicity, do react predominantly as carbanions [6, 13-16]. On the other hand, less nucleophilic carbenoids such as zinc or rhodium linked ones exhibit preferentially an electrophilic behavior [4, 22].

In recent years, our group launched a research program [23] focused on the use of carbenoid-type reagents for the homologation of different carbon (Weinreb amides [24-32], ketones [33, 34], isocyanates [35-38]) or heteroatom electrophiles [39] for preparing in a single step $\alpha$ halo or rearranged (thereof) derivatives [40]. We observed a paramount importance of the conditions employed for generating the carbenoid and, herein, we disclose full details on how to prepare and use these highly reactive species under Barbier type conditions [41, 42].

\section{Results and discussion}

We evaluated the employment of a syringe pump, as a practical tool to modulate the addition rate of organolithium and its influence in carbenoid-mediated homologation reactions. A straightforward strategy to yield halohydrins requires the treatment of an aldehyde or a ketone with halocarbenoids. Reactions involving carbenoids need an excess of both halomethyl precursor and Li-source to overcome the limiting instability after their generation at $-78{ }^{\circ} \mathrm{C}$ [18]. The carbenoid species were generated in situ, by adding $\mathrm{MeLi}-\mathrm{LiBr}$ (2.8 equiv) — using an automatic syringe pump-to a solution of $\mathrm{ICH}_{2} \mathrm{Cl}(3.0$ equiv) and electrophile (1.0 equiv). Accordingly, we firstly evaluated the reproducibility of the reaction (reported by Matteson in 1986) [43] on benzaldehyde (1) being the substrate endowed with an excellent electrophilic profile. Moreover, for comparative purposes, we performed an exploratory reaction, adopting a manual addition of the organolithium reagent $(\mathrm{MeLi}-\mathrm{LiBr})$, at $-78^{\circ} \mathrm{C}$. The synthetic protocol led us to obtain the desired chlorohydrin 2a, in relatively low yield (54\%). Considering this result, we directed our efforts towards the identification of the optimal conditions to achieve a complete conversion of benzaldehyde into the corresponding $\mathbf{2 a}$, exploiting a syringe pump. Different temperatures-ranging from -78 to $20{ }^{\circ} \mathrm{C}$-were screened to evaluate the conversion of the aldehyde into the desired product and, the subsequent generation and distribution of side-products (i.e., epoxide $\mathbf{3}$ or alcohol 4). The so-obtained chloromethyllithium 
Table 3 Study of $\mathrm{ICH}_{2} \mathrm{Cl}$ reactivity toward electrophiles at different temperature

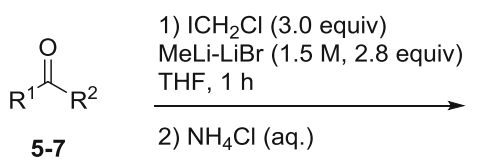

$5 \mathrm{R}^{1}=\mathrm{Bn}-, \mathrm{R}^{2}=\mathrm{H}$

$6 \mathrm{R}^{1}=\mathrm{Ph}-, \mathrm{R}^{2}=-\mathrm{N}(\mathrm{OMe}) \mathrm{Me}$

$7 \mathrm{R}^{1}, \mathrm{R}^{2}=\mathrm{C}_{5} \mathrm{H}_{8}$

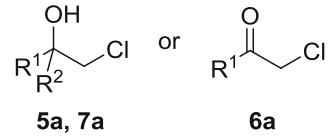

5a $R^{1}=B n-, R^{2}=H$

6a $\mathrm{R}^{1}=\mathrm{Ph}$ -

7a $\mathrm{R}^{1}, \mathrm{R}^{2}=\mathrm{C}_{5} \mathrm{H}_{8}$

\begin{tabular}{|c|c|c|c|c|}
\hline Entry & $T /{ }^{\circ} \mathrm{C}$ & $5 a$ & $6 a$ & $7 a$ \\
\hline 1 & -78 & 64 & 82 & 93 \\
\hline 2 & -65 & 65 & 74 & 95 \\
\hline 3 & -55 & 54 & 72 & 97 \\
\hline 4 & -45 & 68 & 69 & 97 \\
\hline 5 & -35 & 68 & 59 & 94 \\
\hline 6 & -25 & 70 & 51 & 91 \\
\hline 7 & -15 & 57 & 33 & 85 \\
\hline 8 & -5 & 40 & 38 & 59 \\
\hline 9 & 0 & 44 & 21 & 59 \\
\hline
\end{tabular}

Numbers signify conversion (\%) of $\mathbf{5 , 6}$, and $\mathbf{7}$ towards their corresponding homologated product $\mathbf{5 a}, \mathbf{6 a}, \mathbf{7 a}$ based on ${ }^{1} \mathrm{H}$ NMR calculations

Table 4 Use of additives/salts

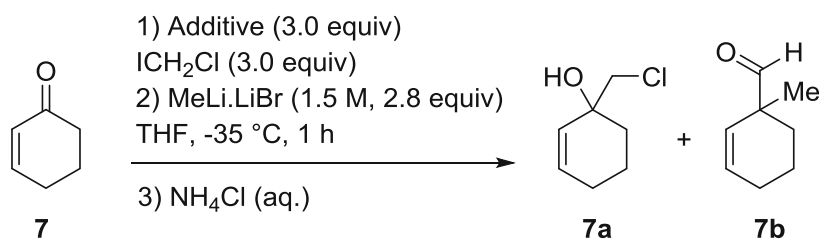

\begin{tabular}{|c|c|c|c|c|c|}
\hline Entry & Additive & $T /{ }^{\circ} \mathrm{C}$ & 7 & $7 \mathbf{a}$ & $7 b$ \\
\hline REF & REF & -35 & 4 & 94 & 2 \\
\hline 1 & $\mathrm{LiCl}(0.5 \mathrm{M}$ in THF $)$ & -35 & 18 & 81 & 1 \\
\hline 2 & $\mathrm{LiBr}(1.5 \mathrm{M}$ in $\mathrm{THF})$ & -35 & 17 & 68 & 5 \\
\hline 3 & $\mathrm{Ti}(\mathrm{O} i \mathrm{Pr})_{4}$ & -35 & 44 & 56 & 0 \\
\hline 4 & $\mathrm{MnCl}_{4} \mathrm{Li}_{2}(0.5 \mathrm{M}$ in THF $)$ & -35 & 68 & 32 & 0 \\
\hline 5 & TMEDA & -35 & 7 & 92 & 1 \\
\hline 6 & $\mathrm{LaCl}_{3}$ & -35 & 11 & 86 & 3 \\
\hline 7 & $\mathrm{CeCl}_{3}$ & -35 & 17 & 83 & 0 \\
\hline 8 & $\mathrm{FeCl}_{3}$ & -35 & 47 & 53 & 0 \\
\hline 9 & $\mathrm{CoCl}_{2}$ & -35 & 22 & 78 & 0 \\
\hline 10 & $\mathrm{NiCl}_{2}$ & -35 & 26 & 73 & 1 \\
\hline 11 & $\mathrm{PbCl}_{2}$ & -35 & 16 & 83 & 1 \\
\hline 12 & $\mathrm{InCl}_{3}$ & -35 & 20 & 80 & 0 \\
\hline 13 & $\mathrm{LiClO}_{4}$ & -35 & 0 & $>99$ & 0 \\
\hline 14 & $\mathrm{CuCl}$ & -35 & 19 & 79 & 2 \\
\hline 15 & $\mathrm{CuI}$ & -35 & 37 & 58 & 5 \\
\hline 16 & $\mathrm{SbCl}_{3}$ & -35 & 43 & 57 & 0 \\
\hline 17 & $\mathrm{CdCl}_{2}$ & -35 & 15 & 85 & 0 \\
\hline 18 & $\mathrm{MeNH}\left(\mathrm{CH}_{2}\right)_{2} \mathrm{NHMe}$ & -35 & 38 & 54 & 8 \\
\hline 19 & HMPA & -35 & 20 & 51 & 2 \\
\hline 20 & DMPU & -35 & 17 & 81 & 2 \\
\hline
\end{tabular}

Numbers signify conversion (\%) of $\mathbf{7}$ to $\mathbf{7 a}$ and $\mathbf{7 b}$ based on ${ }^{1} \mathrm{H}$ NMR calculations 


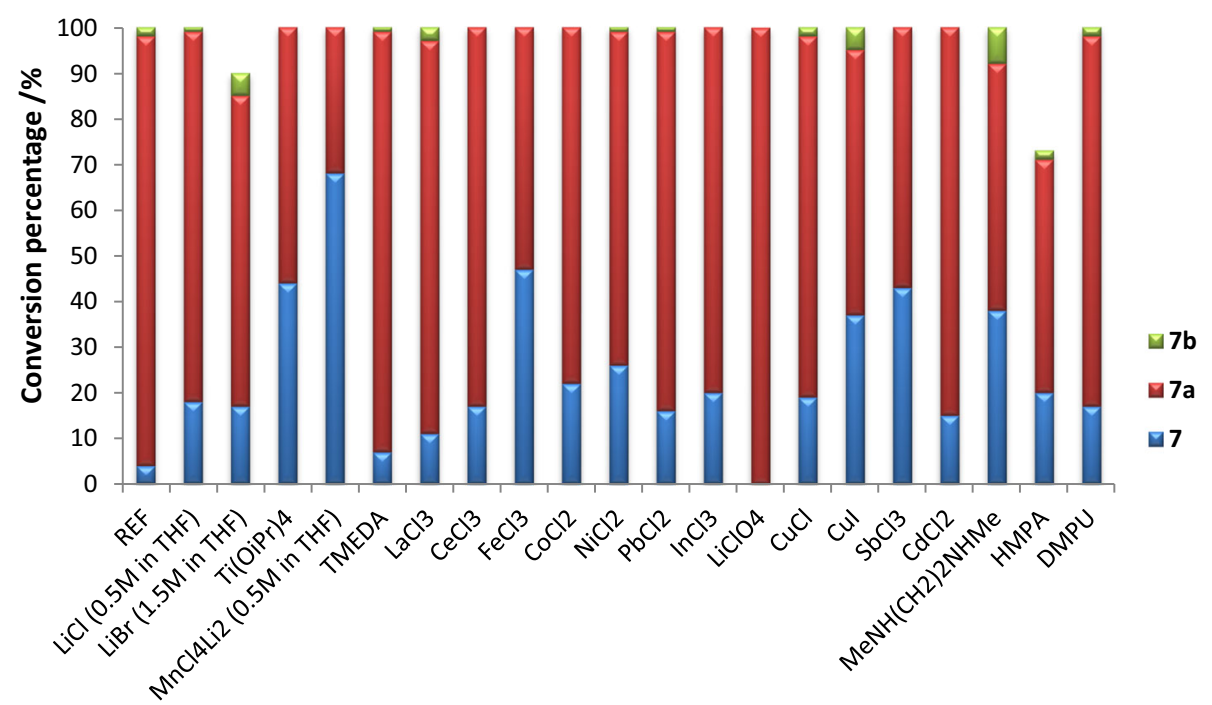

Additives

Fig. 1 Use of additives/salts

promptly reacts with the aldehyde present in the reaction environment affording chlorohydrin $\mathbf{2 a}$.

$\mathrm{LiCH}_{2} \mathrm{Cl}$-mediated homologations show the best compromise between stability and reactivity at $-78^{\circ} \mathrm{C}$. Nevertheless, the syringe pump-mediated addition of the lithium reagent allows with a rate of $0.200 \mathrm{~cm}^{3} / \mathrm{min}$ to increase the reaction temperature up to $-15^{\circ} \mathrm{C}$ (Table 1 , entries 1-6 and 8), obtaining the corresponding homologated product $\mathbf{2 a}$ in good yield. Conversely, increasing the temperature from -5 to $20{ }^{\circ} \mathrm{C}$ (Table 1 , entries 9-11), the homologated product $\mathbf{2 a}$ is gradually converted into epoxide 3 via an internal $S_{N} 2$ reaction and the formation of 4 is increased due to the competitive attack of MeLi to the carbonyl [44]. Increasing the rate from 0.200 to $0.400 \mathrm{~cm}^{3} /$ min (Table 1 , entry 7) at $-25{ }^{\circ} \mathrm{C}$ resulted in an excellent conversion into $\mathbf{2 a}$ and no formation of $\mathbf{4}$ was detected. As the addition rate of $\mathrm{MeLi}-\mathrm{LiBr}$ was reduced to $0.050 \mathrm{~cm}^{3}$ / min at $20{ }^{\circ} \mathrm{C}$ (Table 1 , entry 12 ), we observed a higher conversion of $\mathbf{2 a}$ into epoxide $\mathbf{3}$, and reduced attack of MeLi to the aldehyde. The results obtained can be translated to a higher control for generating the Li-carbenoid species at elevated temperatures as well as maintaining a good stability and reactivity. In turn, for this specific case, the thermal instability of halohydrin $\mathbf{2 a}$ lies on the boundary of -25 to $-15^{\circ} \mathrm{C}$.

We then studied the effect of temperature on the reactivity of halocarbenoids generated by different halomethyl sources to compare the behavior of Li-carbenoid species.

The use of diiodomethane for generating iodomethyllithium showed good results under the reaction condition below $-55^{\circ} \mathrm{C}$ (Table 2, entries 1-3). The increase of the temperature favored the formation of the corresponding epoxide 3. Notably, compound 4 does not exceed $18 \%$ even at $0{ }^{\circ} \mathrm{C}$ (Table 2, entries 7-9).

Difficulties in controlling the generation of bromomethyllithium carbenoid arose when using $\mathrm{CH}_{2} \mathrm{Br}_{2}$ as dihalomethane. Evidently, the Li-carbenoid is generated at a minor extent in comparison with $\mathrm{ICH}_{2} \mathrm{Cl}$ and the reaction is dominated by a direct nucleophilic addition of MeLi on carbonyl at temperature up to $-25^{\circ} \mathrm{C}$ (Table 2, entries 6-9). $\mathrm{ICH}_{2} \mathrm{Br}$ was then used as alternative bromomethyl source, showing similar results to $\mathrm{ICH}_{2} \mathrm{Cl}$, albeit in slightly lower conversion into bromohydrin 2c. It showed a good control in generating the bromomethyllithium carbenoid and maintaining a good reactivity until $-35{ }^{\circ} \mathrm{C}$ (Table 2 , entry 5). Increasing the temperature, resulted in the bromohydrin ring closure to afford epoxide $\mathbf{3}$ (Table 2, entry 7) and at $0{ }^{\circ} \mathrm{C}$ no bromohydrin 2 was anymore detected (Table 2, entry 9). At higher temperature, MeLi-LiBr possesses a higher reactivity towards benzaldehyde than $\mathrm{ICH}_{2} \mathrm{Br}$; in fact compound 4 represents the main reaction product at $0{ }^{\circ} \mathrm{C}$ (Table 2, entry 9). In the light of these data, $\mathrm{ICH}_{2} \mathrm{Cl}$ remains the best source for generating and maintaining a good reactivity of the Li-carbenoid, $\mathrm{LiCH}_{2} \mathrm{Cl}$, towards benzaldehyde.

With the aim to widen the stability/reactivity study employing syringe pump, other electrophiles were subjected to the previous reaction conditions. 2-Phenylacetaldehyde (5), phenyl Weinreb amide (6), and cyclohexenone (7) were selected for this scope.

Extending the chain with one carbon atom, 2-phenylacetaldehyde resulted in a quasi-stable conversion towards 5a although in a minor consent when compared to benzaldehyde 1 . 
Table 5 Concentration dependency in the homologation of $\mathbf{7}$ towards $\mathbf{7 a}$

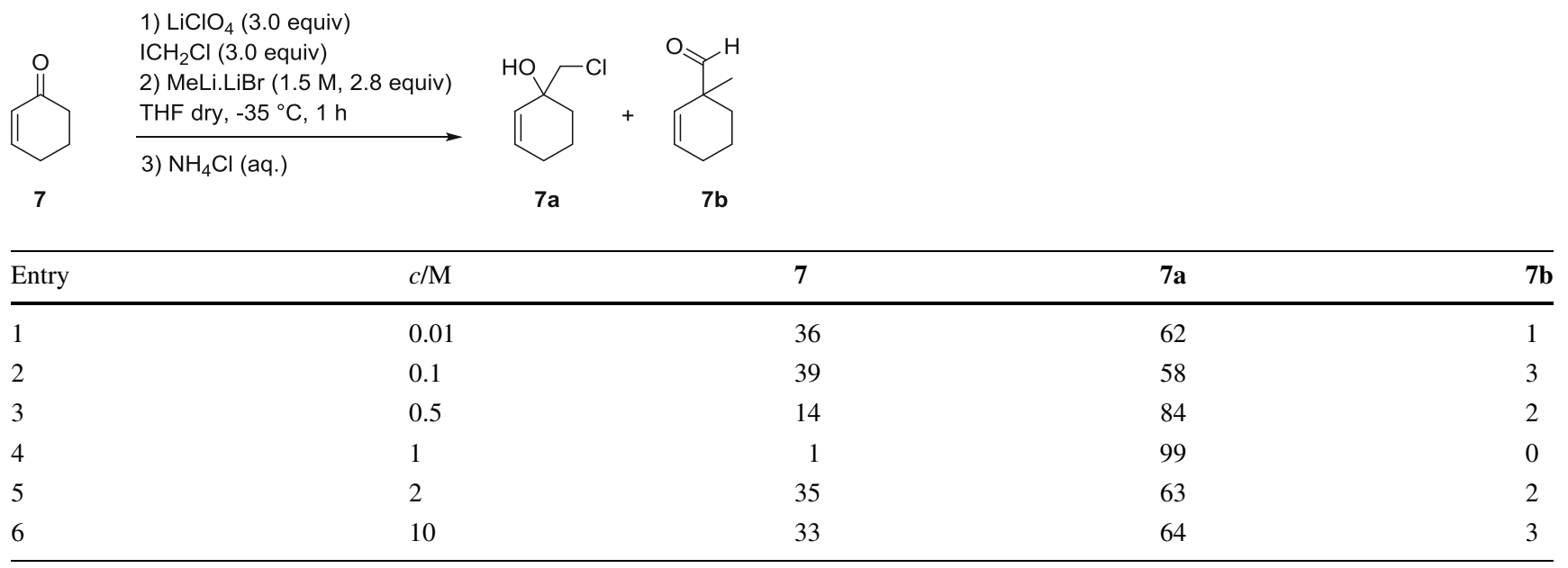

Numbers signify conversion (\%) of $\mathbf{7}$ to $\mathbf{7 a}$ and $\mathbf{7 b}$ based on ${ }^{1} \mathrm{H}$ NMR calculations

Afterwards, the homologation of Weinreb amides-a class of acylating agents particularly suited for $\alpha$-substituted organolithium reagents [45-48] — was evaluated. $N$ Methoxy- $N$-methylbenzamide (6) showed rather good results until $-45^{\circ} \mathrm{C}$, where the conversion starts to decrease, however, maintaining $21 \%$ conversion at $0{ }^{\circ} \mathrm{C}$ (Table 3, entries 5-9).

The $\alpha, \beta$-unsaturated cyclic ketone 7 was then chosen as electrophile, due to our previous interest in its challenging reactivity [40]. Surprisingly, it showed a very good stability profile even at temperature close to $0{ }^{\circ} \mathrm{C}$ and practically the same reactivity of benzaldehyde with chloromethyllithium (Table 3, entries 5-9). To reach full conversion of cyclohexenone into chlorohydrin $\mathbf{7 a}$, different additives were tested. They could promote the formation and improve the stability of the Li-carbenoid and ultimately increase the electrophilicity of the cyclohexenone.

As shown in Table 4 and in Fig. 1, the reference conditions were set at $-35^{\circ} \mathrm{C}$ for $1 \mathrm{~h}$, upon which small conversion into aldehyde $\mathbf{7 b}$ (as a consequence of the Meinwald rearrangement) was started to be observed [40].

From the obtained results, we can conclude that the addition of additives has almost no beneficiary effect on the conversion towards 7a. Nevertheless, there are a few cases worth mentioning. Although entries 2, 15, and 18 (Table 4, Fig. 1) show a decrease in the homologated product $\mathbf{7 a}$; they also resulted in a slightly higher conversion into the corresponding aldehyde 7b. Surprisingly, full conversion of cyclohexenone $\mathbf{7}$ into $\mathbf{7 a}$ was observed only when lithium perchlorate $\mathrm{LiClO}_{4}$ (Table 4, entry 15; Fig. 1) was used. With this result in hand, we examined the concentration dependency of cyclohexenone in combination with $\mathrm{LiClO}_{4}$. As reported in Table 5, the optimal concentration
(Table 5, entry 4) was found to be $1 \mathrm{M}$ and it represents the concentration used in all the previous experiments.

\section{Conclusions}

The well-known instability of lithium halocarbenoids has represented a significant challenge for their employment in synthesis [49]. Despite the usefulness, the requirement for strict conditions for counterbalancing the degradative $\alpha$ elimination had somehow constituted the main limitation, thus obscuring the innate potential. In this study, we identified the ideal conditions (stoichiometry, temperature, syringe pump) for finely tuning their generation and reactivity towards common carbon electrophiles.

Acknowledgements Open access funding provided by University of Vienna. We are grateful to the University of Vienna for financial support.

Open Access This article is distributed under the terms of the Creative Commons Attribution 4.0 International License (http://creative commons.org/licenses/by/4.0/), which permits unrestricted use, distribution, and reproduction in any medium, provided you give appropriate credit to the original author(s) and the source, provide a link to the Creative Commons license, and indicate if changes were made.

\section{References}

1. Li JJ (2009) Name reactions for homologation. Wiley, Hoboken

2. Candeias NR, Paterna R, Gois PMP (2016) Chem Rev 116:2937

3. Molitor S, Gessner VH (2016) Angew Chem 128:7843

4. Boche G, Lohrenz JCW (2001) Chem Rev 101:697

5. Capriati V, Florio S (2010) Chem Eur J 16:4152 
6. Braun M (2004) Lithium carbenoids. In: Rappoport Z, Marek I (eds) The chemistry of organolithium compounds, vol 1. Wiley, Chichester, p 829

7. Closs GL, Moss RA (1964) J Am Chem Soc 86:4042

8. Köbrich G (1972) Angew Chem Int Ed 11:473

9. Köbrich G, Akhtar A, Ansari F, Breckoff WE, Büttner H, Drischel W, Fischer RH, Flory K, Fröhlich H, Goyert W, Heinemann H, Hornke I, Merkle HR, Trapp H, Zündorf W (1967) Angew Chem Int Ed 6:41

10. Capriati V (2014) Modern lithium carbenoid chemistry. In: Moss RA, Doyle MP (eds) Contemporary carbene chemistry. Wiley, Hoboken, pp 327-362

11. Blakemore PR, Hoffmann RW (2018) Angew Chem Int Ed 57:390

12. Siegel H (1982) Lithium halocarbenoids-carbanions of high synthetic versatility. Topics in current chemistry, vol 106. Springer, Berlin

13. Kupper C, Molitor S, Gessner VH (2014) Organometallics 33:347

14. Molitor S, Becker J, Gessner VH (2014) J Am Chem Soc 136:15517

15. Molitor S, Feichtner K-S, Kupper C, Gessner VH (2014) Chem Eur J 20:10752

16. Molitor S, Gessner VH (2015) Synlett 26:861

17. Stephens CL, Nyquist HL, Hardcastle KI (2002) J Org Chem 67:3051

18. Pace V (2014) Aust J Chem 67:311

19. Pace V, Holzer W, De Kimpe N (2016) Chem Rec 16:2061

20. Simmons HE, Smith RD (1958) J Am Chem Soc 80:5323

21. Lebel H, Marcoux J-F, Molinaro C, Charette AB (2003) Chem Rev 103:977

22. Charette AB, Beauchemin A (2004) Simmons-Smith cyclopropanation reaction. In: Overman LE (ed) Organic reactions. Wiley, Chichester

23. Pace V, Castoldi L, Monticelli S, Rui M, Collina S (2017) Synlett 28:879

24. Pace V, Holzer W, Verniest G, Alcántara AR, DeKimpe N (2013) Adv Synth Catal 355:919

25. Pace V, Castoldi L, Holzer W (2013) J Org Chem 78:7764

26. Parisi G, Colella M, Monticelli S, Romanazzi G, Holzer W, Langer T, Degennaro L, Pace V, Luisi R (2017) J Am Chem Soc 139: 13648

27. Mamuye AD, Castoldi L, Azzena U, Holzer W, Pace V (2015) Org Biomol Chem 13:1969
28. Castoldi L, Holzer W, Langer T, Pace V (2017) Chem Commun 53:9498

29. Pace V, Murgia I, Westermayer S, Langer T, Holzer W (2016) Chem Commun 52:7584

30. Senatore R, Ielo L, Urban E, Holzer W, Pace V (2018) Eur J Org Chem. https://doi.org/10.1002/ejoc.201800095

31. Castoldi L, Ielo L, Hoyos P, Hernáiz MJ, De Luca L, Alcántara AR, Holzer W, Pace V (2018) Tetrahedron 74:2211

32. Senatore R, Castoldi L, Ielo L, Holzer W, Pace V (2018) Org Lett 20:2685

33. Pace V, Castoldi L, Holzer W (2014) Adv Synth Catal 356:1761

34. Pace V, Castoldi L, Mamuye AD, Langer T, Holzer W (2016) Adv Synth Catal 358:172

35. Pace V, Castoldi L, Holzer W (2013) Chem Commun 49:8383

36. Pace V, Monticelli S, de la Vega-Hernandez K, Castoldi L (2016) Org Biomol Chem 14:7848

37. Pace V, de la Vega-Hernández K, Urban E, Langer T (2016) Org Lett 18:2750

38. Pace V, Castoldi L, Mamuye AD, Holzer W (2014) Synthesis 46:2897

39. Pace V, Pelosi A, Antermite D, Rosati O, Curini M, Holzer W (2016) Chem Commun 52:2639

40. Pace V, Castoldi L, Mazzeo E, Rui M, Langer T, Holzer W (2017) Angew Chem Int Ed 56:12677

41. Degennaro L, Fanelli F, Giovine A, Luisi R (2015) Adv Synth Catal 357:21

42. Hafner A, Mancino V, Meisenbach M, Schenkel B, Sedelmeier J (2017) Org Lett 19:786

43. Sadhu KM, Matteson DS (1986) Tetrahedron Lett 27:795

44. Pace V, Castoldi L, Hoyos P, Sinisterra JV, Pregnolato M, Sánchez-Montero JM (2011) Tetrahedron 67:2670

45. Nahm S, Weinreb SM (1981) Tetrahedron Lett 22:3815

46. Pace V, Holzer W, Olofsson B (2014) Adv Synth Catal 356:3697

47. Pace V, Holzer W (2013) Aust J Chem 66:507

48. Pace V, Castoldi L, Alcantara AR, Holzer W (2013) RSC Adv 3:10158

49. Castoldi L, Monticelli S, Senatore R, Ielo L, Pace V (2018) Homologation chemistry with $\alpha$-substituted organometallic reagents: chemocontrol, new concepts and (solved) challenges. Chem Commun. https://doi.org/10.1039/C8CC02499E 